\title{
Learning from practice: using case-study research towards post-industrial landscape redevelopment theory
}

\author{
L. Loures ${ }^{1,2}$, T. Panagopoulos ${ }^{1}$, J. Nunes ${ }^{2}$ \& A. Viegas ${ }^{3}$ \\ ${ }^{I}$ CIEO, Research Center for Spatial and Organizational Dynamics, \\ University of Algarve, Portugal \\ ${ }^{2}$ C3I, Centro Interdisciplinar de Investigação e Inovação, \\ Polytechnic Institute of Portalegre, ESAE, Portugal \\ ${ }^{3}$ Faculty of Sciences and Technology, University of Algarve, Portugal
}

\begin{abstract}
In a period when the environmental situation, despite all the well-being indications, is of concern, the increasing urbanization coupled with global issues of climate change, lack of water, environmental degradation and social segregation demands a deeper look at spatial planning and landscape redevelopment. In this scenario, driving the sustainable urban development agenda is a shared concern for the future of the planet. However, while the need to change is generally accepted, sustainability continues to be hard to define and still more difficult to apply. As it has been widely discussed, the effects of the globalization of industry over the past decades had a profound effect on former industrial areas all over the world, producing a vast array of obsolete industrial facilities and the various impacts which are generated from them. For this reason, the recognition that the reutilization of derelict landscapes, within urban settlements of all sizes, constitutes a proactive strategy to struggle both the continuous urban growth and the loss of public and private open space, promoting the development of more human, safe, attractive and competitive cities constitutes an important step towards landscape sustainability. This paper presents a methodology towards the definition of an improved post-industrial landscape redevelopment theory based on the case study research method. The proposed approach and the way it is applied in this paper may be empirically described as research that analyses successful post-industrial landscape redevelopment design approaches, in order to build a set of design principles that
\end{abstract}


might inform and serve as a theoretical basis to the redevelopment of similar landscapes.

Keywords: post-industrial land, urban redevelopment, case-study approach.

\section{Introduction: the status of the post-industrial landscape}

The shift of emphasis from the design of single and isolated objects to the design of larger urban surfaces, thus increasing the impact of the envisioned interventions, highlighted the need to create an original body of landscape architecture theory, providing a structure based on specific principles from which prescriptions for action may be drawn. Under this framework, theoretical reflection and discussion have been identified as an important issue in revitalizing cross-cultural exchange in landscape architecture and urban design. Additionally, the fact, landscape is continuously changing $[1,2]$ as a result of complex and interacting natural processes coupled with planned and unplanned actions by man enlarge this scenario. However, this ongoing landscape transformation - considering not only post-industrial ones - has raised global concerns [3-5], as it is the need to rethink landscape and protect the environment. This is especially true for previously developed areas that are now abandoned or underused. In fact, instead of consuming green lands, public and private representatives need to acknowledge that it is imperious to redevelop "brown lands", giving them a new life, in order to achieve a more sustainable urban setting [6-8].

The relevance and popularity of these land transformation approaches are increasingly recognized, and as referred by Reed (2005, p.15) "nearly every significant new landscape designed in recent years occupies a site that has been reinvented and reclaimed from obsolescence or degradation, as cities in postindustrial era remake and redefine their outdoor spaces" [9]. Consequently questions such as: What should be done with these landscapes? Which functions might these areas acquire in the future? What makes these spaces underutilized? What obstacles keep these landscapes from being transformed? Who is responsible for transforming them? Who is best qualified to do it? Is this process a single profession endeavor? Among others, remain to be answered.

For this reason, new methodologies and frameworks are needed. In a period when “(...) that seemingly old-fashioned term landscape has curiously come back to vogue" [10], it is urgent to reinvent the way in which these postindustrial landscapes are transformed, considering not only environmental issues but also historic and cultural values, economic opportunities, and social needs. The origin of this growing concern may be traced from a period when industry, became one of the main protagonists in the transformation of the city [11].

The globalization of industry had a profound effect on industrial areas all over the world, contributing to the appearance of several derelict and underused postindustrial landscapes [12] that contribute to reduce the development potential and the quality of life [13]. This scenario, coupled with urban growth (urban population in the world was approximately 2.4 billion in 1995 number that is expected to duplicate at about the year 2025) and with the population concentration in urban areas [14], Landscape Architects and other planning 
specialists are faced with a great challenge: How to plan the future of those postindustrial landscapes facing the "new" growth management paradigm? Communities, cities and regions must accommodate economic development and population growth while sustaining and enhancing the spirit of the community, the sense of place, and the physical environment - the answer to this question is far from being simple, but the reuse of post-industrial sites, in order to develop multifunctional landscapes, instead of consuming new ones is seen as a great possibility to help achieving those goals [15].

The fact that these urban areas became economically and environmentally degraded and socially distressed through industrial contamination [16] make clear that redevelopment projects should enable the redefinition of these landscapes through community-based, interdisciplinary action that integrates multifunctional longer-term solutions based on social, economic and ecological objectives, as it has happened throughout several countries in the world (figures 1 to 4 ).

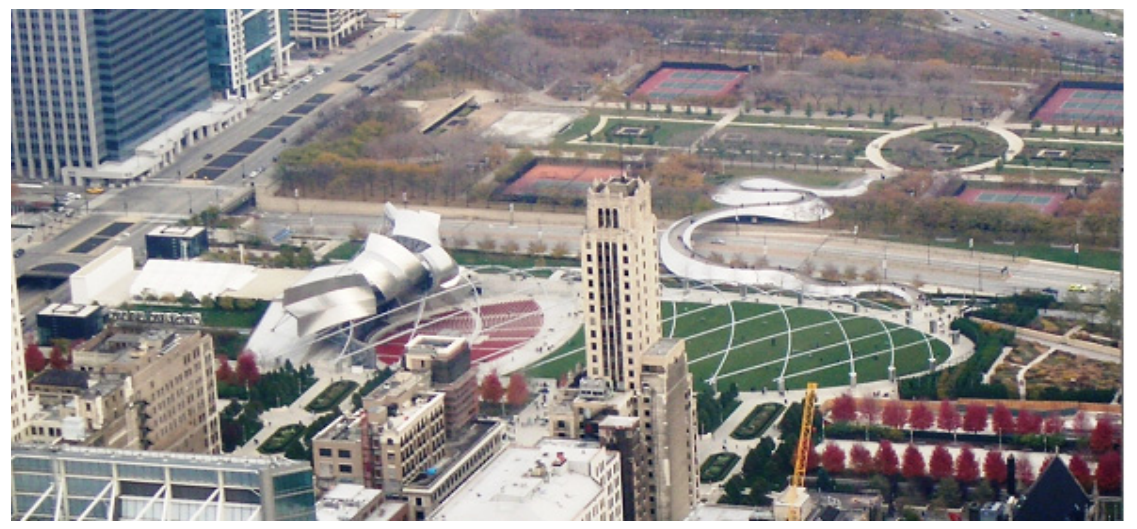

Figure 1: Millennium Park, Chicago - view from Sears Tower. Used with permission of Luís Loures, all rights reserved.

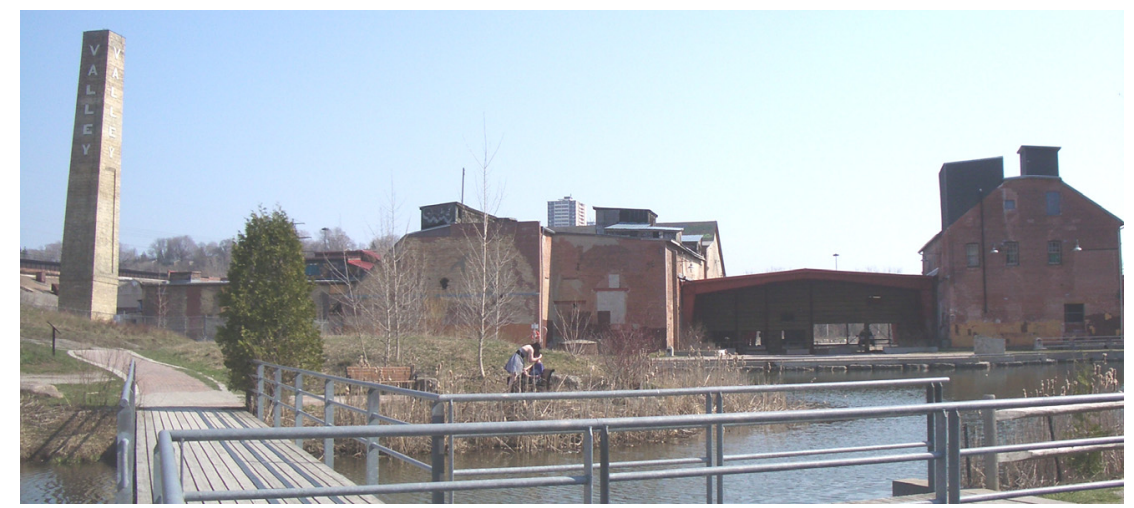

Figure 2: $\quad$ South view of the Brick Works project. Environmental restoration and industrial heritage protection were considered at the same level. Used with permission of Luís Loures, all rights reserved. 


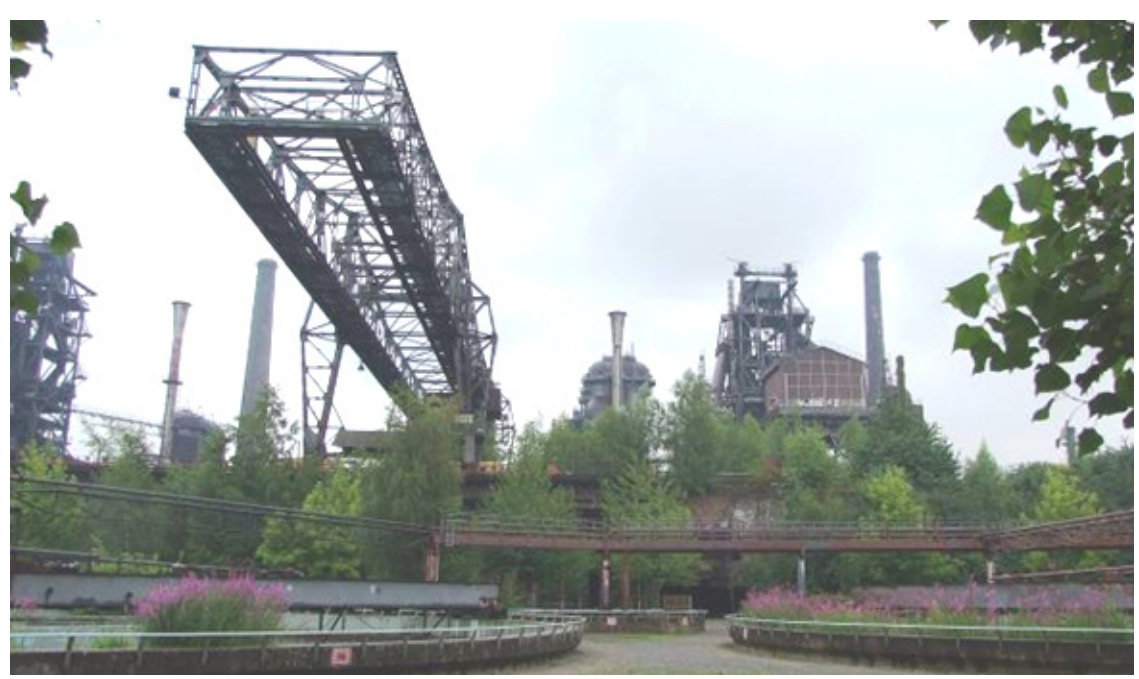

Figure 3: Duisburg Nord Park. Used with permission of Luís Loures, all rights reserved.

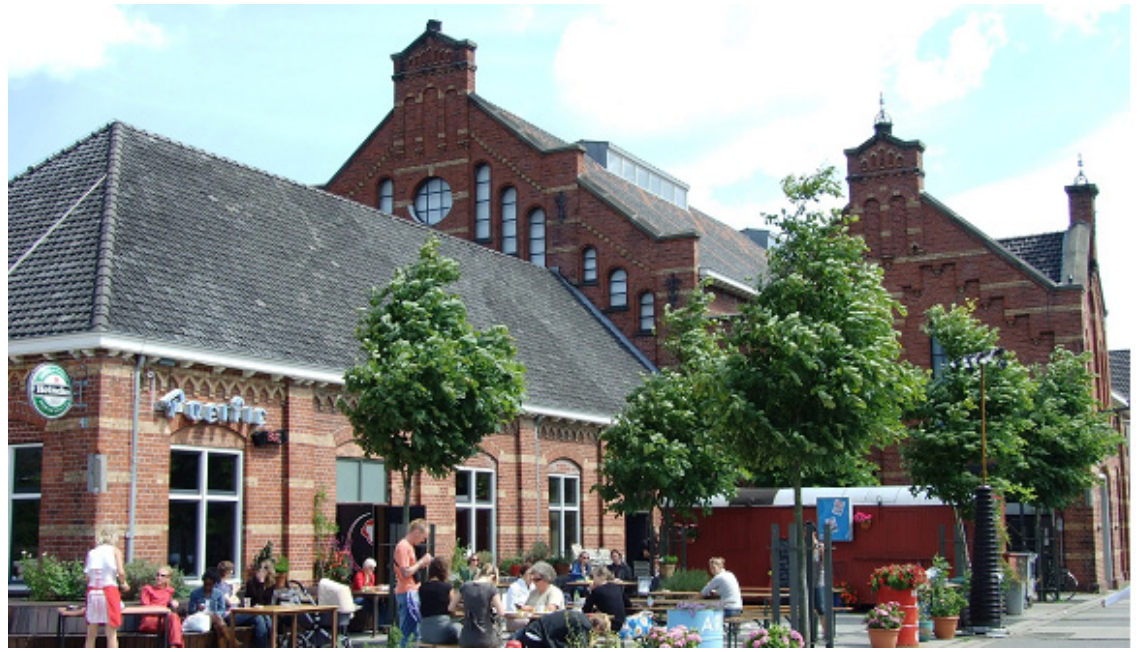

Figure 4: Westergasfabriek, Amsterdam. Used with permission of Luís Loures, all rights reserved.

\section{Methodology: envisioned framework}

As it has long been realized urban planning and open space preservation are part of the same process and the most effective way to protect open space is by effectively containing and managing urban growth [17]. In this regard, land transformation policies, strategies and methodologies have been considered an 
important tool for urban containment, fostering urban redevelopment and revitalization [18-20].

However, these contributions and the principles they integrate, have not been adequately assessed regarding post-industrial land transformation efforts. Still, this approach may be considered a proficient approach to address urban sprawl, increasingly viewed as significant and growing land-use problem that encompass a wide range of social, economic and environmental issues [17, 21, 22].

Throughout the last decades several researchers and academics have been committed with the development of strategies that enable the creation of better landscape transformation projects, which are normally excessively subjective and dependent on the designer's determination, fact that is considered to be a limitation. For this reason new frameworks and methodologies are required.

However, these methodologies require the use of several methods throughout the research, including quantitative and qualitative strategies, which at their best are not linear methods but circle back upon issues, principles, and information, as many times as necessary [23].

In this regard, considering the approach according to which, learning by experience is considered a proficient tool for urban redevelopment the proposed methodology (figure 5) was divided in two main sections: case study research (developed projects - learning by experience) and practical case studies (site specific characteristics and uniqueness of the place).

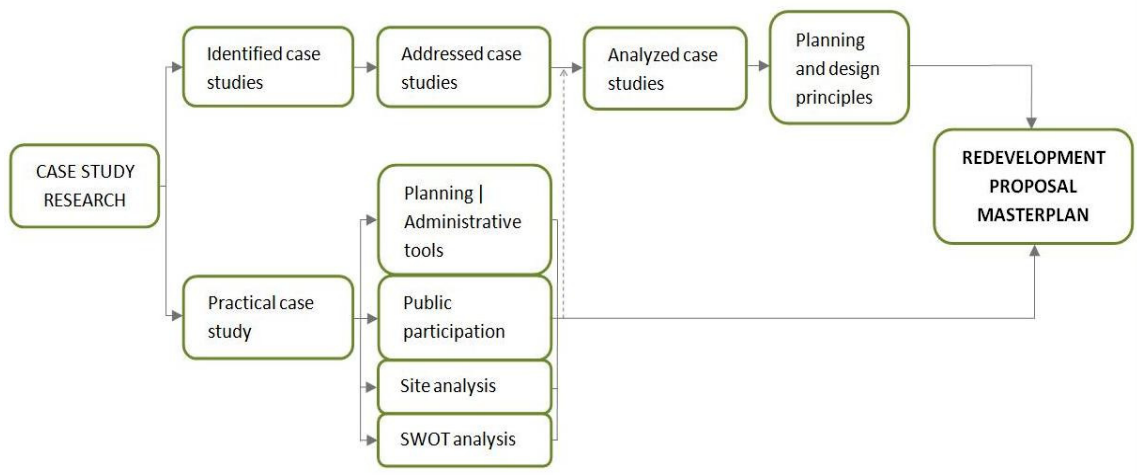

Figure 5: $\quad$ Proposed methodological scheme.

As is perceptible case study research and the analysis of best-practice examples of post-industrial redevelopment constitute the basis of the proposed framework.

Regarding this type of analysis, Yin (1994) presented five research strategies (although acknowledging the existence of several others) on his book "Case Study Research - Design and Methods": experiment; survey; archival analysis; history and case study [24].

Nonetheless, the Case Study Research method is considered by several authors a very important research strategy [24-27], which allows not only the 
analysis and comparison among similar case studies, but also the development of a systemic analysis, where the subjective component is much smaller.

These intrinsic characteristics enable the use of this method in various fields of knowledge as it is the case of medical research, sociology, engineering, planning, architecture and landscape architecture [28]. Furthermore, according to Francis (1999 and 2001) this method is a very useful tool to study and analyse existing projects and the way in which certain problems and design constrains were solved and which strategies should be followed or avoided [28, 29].

The use of this method will enable the creation of a set of post-industrial landscape redevelopment planning and design principles that may inform the creation of a specific theoretical basis to increase the quality of similar redevelopment proposals [i.e. researching and analysing the practical principles applied in successful post-industrial landscape reclamation projects in order to create a set of principles that will inform the creation of specific design theory.

\section{From theory to practice: brief overview}

Considering the afore-presented methodology the selection of study areas constitutes an essential component of the research, representing an important aspect to the accomplishment of the present study. In this regard, the selection of "best-practice" case studies (as well as the definition of a practical case study area) should consider a set of predefined parameters.

Regarding the selection of "best practice" case studies, the process is anchored in the collection and analysis of as much post-industrial land transformation projects as was possible within the boundaries set by schedule and economic constraints.

In this sense, throughout the investigation as many post-industrial land transformation case studies as possible should be identified. After identifying the project it is necessary first to address the availability of data, and second to verify the possibility to access, collect and use that data. If the necessary information is available, and the case study considered relevant for the research, considering the characteristics of the practical study area, the project will be addressed.

If the number and magnitude of the addressed case studies is significantly high, in order to keep the review manageable, analysis should be limited in several ways. First, the research should focus not only on post-industrial land transformation projects which present higher similarity with the practical study area, but also that considered the pre-design goals | objectives, established throughout the analysis of the practical study area. Second, the selected projects should obey to a set of selection principles that included:

- transferability and/or contextual relevance to the study area (post-industrial land transformation) considering not only the specific principles and frameworks of the design strategy used in the redevelopment process, but also size, social diversity, cultural relevance and impact of the project;

- the establishment of a direct contact at least with a specialist connected with the project (i.e. designer or project coordinator) is considered mandatory, so that the 
inferential ideas and conclusions presented during case study description and analysis, regarding not only the design strategy adopted, but also the presented solutions, the construction options, the program, and specially the planning and design principles used, could be confirmed by a specialist with precise and effective knowledge about the project;

- project implementation - the project should be implemented or partially implemented (several times the design solutions presented in international competitions tend to be increasingly iconographic and sometimes arguably unsustainable);

- site visits - the site of the project should be visited by the person responsible for the analysis of the case study, whenever possible more than once, in order to analyze the way the space functions and how people use it, performing some formal interviews with the users;

Considering these principles and even if there is an inevitable value judgement in any process to ascertain relative importance, the method is considered to bring a degree of objectivity and transparency to the assessment, enabling the selection of the cases that respond better to research objectives.

Still, given that the proposed methodological framework comprises the analysis of multiple-case studies, it is essential to have a protocol for all studies [24]. In this sense and still according to the same author a typical protocol should integrate the following sections: an overview of the case study project; field procedures; case study questions; and a guide for the case study report. Considering this information, for each case study the subsequent aspects should be investigated and analyzed: location; design team; project typology and use; size; brief description of the project background | history; significance and uniqueness of the project; goals; program and design strategy; lessons learned and project limitations.

After the analysis of each of the selected case studies, following the aforementioned protocol the planning and design principles used in the redevelopment proposal will be heuristically defined, using an approach similar to the one proposed by Lang (1994) in order to identify normative theories in urban planning [30]. After identification each planning and design principle will be described according to the ideas and definitions expressed in the literature. Whenever possible, this definition should be gauged with the design team of the project in which the principle was identified, in order to grant a more precise and objective information regarding the definition and the goals of each principle.

\section{Final remarks}

It is increasingly recognized that the redevelopment of derelict post-industrial areas should follow design principles that promote sustainability, reduce negative environmental impacts, and foment economic prosperity, social inclusion and a better quality of life, reason why the interlocking relationship between design and management is a particularly important feature in future urban design processes and strategies. 
Nonetheless, a deeper analysis of the redevelopment process highlights that there is a general lack of 'strategic vision' in today's planning activities both regarding communities, townscapes, and green spaces as a whole. With that being said, the redevelopment of post-industrial landscapes must be approached with the necessities of the future generations. In conscious opposition to the lack of community visioning that is recognized; the envisioned framework is considered to enable the development of solutions that seek to satisfy a time, which is not so far off, where post-industrial land transformation will become a necessity in the urban landscape.

Still, even if it is acknowledged that the redevelopment of underused areas might constitute a feasible way of dealing with the progressive urbanization, there is still a question mark hanging over what kind of redevelopment these spaces can look forward to. As argued by several authors [6-8], land transformation projects should redefine the post-industrial landscape through community-based, interdisciplinary action that integrates multifunctionality, industrial heritage and public participation on the longer-term solutions based on socio-cultural, economic and environmental and aesthetic objectives.

In this regard, land use planning methods should identify the right balance and timing between pro-active policies and re-active regeneration projects, and between legislative, administrative and educational policy engines, engaging citizens, authorities and markets in a process of reinvention of urban living. In these circumstances post-industrial landscapes if integrated properly in the planning process, may become a driving force for urban growth, fostering a positive image that will attract investors as well as tourists.

However, research has shown that, even if, throughout the last decades several researchers and academics have been committed with the development of strategies and frameworks to enable the creation of better landscape transformation projects, redevelopment proposals still tend to be excessively subjective and directly dependent on the designer's determination and intentions. In this regard the application of the proposed methodological framework is considered to be a proficient tool to decrease design's subjectivity, creating a common ground in which different fields of knowledge might communicate enhancing the quality of future redevelopment proposals.

Still, even if the proposed methodology will enable the assessment of the environmental, economic and social dimensions of sustainability at the same level, fostering sustainable development, it will just function as a complement of designer expertise, since the application of any of the identified planning and design principle is site specific and dependent on designer creativity.

In conclusion it is believed that the presented approach will reinforce the quality of post-industrial land transformation projects increasing landscape character and promoting the creation of multifunctional resilient landscapes, capable to incorporate change and enhance life's quality. 


\section{Acknowledgements}

The authors would like to acknowledge financial support given by the Centre for Spatial and Organizational Dynamics (CIEO) and from the Foundation for Science and Technology (FCT).

\section{References}

[1] Jinyan, Z., Xiangzheng, D. and Tianxiang, Y., Landscape Change Detection in Yulin Prefecture. Journal of Geographical Sciences, 14(1): 47-55, 2003.

[2] Pinto-Correia, T., D’Abreu, A. and Oliveira, R., Identificação de Unidades de Paisagem: Metodologia Aplicada a Portugal. In: Finisterra, XXXVI, 72: 195-206, 2001. Retrieved August 12, 2009, from http://www.ceg.ul.pt /finisterra/numeros A 12001-72/72_17.pdf

[3] Czerniak, J., Looking Back at Landscape Urbanism: Speculations on Site. In: Waldheim, C. (Ed.), The Landscape Urbanism Reader. Princeton Architectural Press, New York. pp. 105-123, 2006.

[4] Musacchio, L., Ozdenerol, E., Bryant, M., and Evans, T., Changing landscapes, changing disciplines: seeking to understand interdisciplinarity in landscape ecological change research. Landscape and Urban Planning, 73(4): 326-338, 2005.

[5] Spirn, A., The Language of Landscape. Yale University Press, New Haven, 1998.

[6] De Sousa, C., Turning brownfields into green space in the City of Toronto. Landscape and Urban Planning, 62: 181-198, 2003.

[7] Panagopoulos, T. and Loures, L., Reclamation of derelict industrial land in Portugal: greening is not enough. Book of Abstracts of the 10th European Forum on Urban Forestry, May 16-19, 2007, Gelsenkirchen, Germany. pp. 71-72, 2007.

[8] Portney, K., Taking Sustainable Cities Seriously: Economic Development, the Environment, and Quality of Life in American Cities. MIT Press, Cambridge, 2003.

[9] Reed, P. (Ed.), Groundwell: Constructing the Contemporary Landscape. The Museum of Modern Art, New York, 2005.

[10] Corner, J., Terra Fluxos. In: Waldheim, C. (Ed.), 2006. The Landscape Urbanism Reader. Princeton Architectural Press, New York, 2006.

[11] Rossi, A., The Architecture of the City. MIT Press, Cambridge, 1982.

[12] Antrop, M., Background concepts for integrated landscape analysis. Agriculture Ecosystems and Environment, 77:17-28, 2000a.

[13] Handley, J., The Post-Industrial Landscape. The Groundwork Foundation, Birmingham, 1996.

[14] Antrop, M., Changing patterns in the urbanized countryside of Western Europe. Landscape Ecology, 15: 257-270, $2000 \mathrm{~b}$.

[15] Loures, L. and Panagopoulos T., Recovering Derelict Industrial Landscapes in Portugal: Past Interventions and Future Perspectives. Proceedings of the 
Int. Conf. on Energy, Envir. Ecosystems and Sustainable Development, July 24-26, 2007 Agios Nikolaos, Crete Island, Greece, pp. 116-121, 2007.

[16] Department of Environment, Derelict Land Grant Advice: Derelict Land Grant Policy. London: DoE, 1991.

[17] Bengston, D., Fletcher, J. and Nelson, K., Public policies for managing urban growth and protecting open space: policy instruments and lessons learned in the United States. Landscape and Urban Planning, 69(2-3): 271286, 2004.

[18] Adams, D. and Watkins, C., Greenfields, Brownfields and Housing Development. Blackwell Science Ltd, Oxford, 2002.

[19] Urban Land Institute, Barriers and Solutions to Land Assembly for Infill Development. The Urban Land Institute, Washington DC, 2004.

[20] Willem, K., Taxing land for urban containment: Reflections on a Dutch debate. Land Use Policy. 26(2): 233-241, 2009.

[21] Brueckner, J., Urban Sprawl: Diagnosis and Remedies. International Regional Science Review, 23(2): 160-171, 2000.

[22] Johnson, M., Environmental Impacts of Urban Sprawl: a Survey of the Literature and Proposed Research Agenda. Environment and Planning A 33(4): 717-735, 2001.

[23] Wortham, B., The Way We Think about the Way We Think - Architecture is a Paradigm for Reconsidering Research. Journal of Architectural Education, 61(1): 44-53, 2007.

[24] Yin, R., Case Study Research: design and methods. Sage Publications, London, 1994.

[25] Agranoff, R. and Beryl A., The Comparative Case Study Approach in Public Administration. Research in Public Administration, 1: 203-231, 1991.

[26] George, A., Case Study and Theory Development: The Method of Structured, Focused Comparison. In: Lauren, P. (Eds.), Diplomacy: New Approaches in History, Theory and Policy. Free Press, New York, 1979.

[27] Lucas, W., The Case Survey Method. RAND Corporation, Santa Monica, 1974.

[28] Francis, M., A case study method for landscape architecture. The Landscape Architecture Foundation, Washington DC, 1999.

[29] Francis, M., A Case Study Method for Landscape Architecture. Landscape Journal, 19(2): 15-29, 2001.

[30] Lang, J., Urban Design - The American Experience. John Wiley \& Sons, Inc, New York, 1994. 